\title{
COMPARAÇÃO ENTRE CULTIVARES DE SOJA QUANTO À PREFERENCIA ALIMENTAR DE CEROTOMA ARCUATA E SUSCETIBILIDADE A UM ISOLADO DO VÍRUS DO MOSAICO SEVERO DO CAUPI
}

\author{
Fernando Javier Sanhueza Salas \\ Marcus Vinicius Fachini Lopes ${ }^{1,2}$ \\ Ana Claudia Cotrim Pacheco ${ }^{1,3}$ \\ Maria Mércia Barradas ${ }^{1}$
}

Recebido em 20/01/1999. Aceito em 30/03/1999

\begin{abstract}
RESUMO - (Comparaçâo entre cultivares de soja quanto à preferência alimentar de Cerotoma arcuata e suscetibilidade a um isolado do vírus do mosaico severo do caupi). Entre as viroses que causam prejuízos às culturas de leguminosas no Brasil, principalmente soja (Glycine max), feijāo (Phaseolus vulgaris) e caupi (Vigna unguiculata), inclui-se o mosaico severo do caupi, "cowpea severe mosaic Comovirus" - CpSMV, transmitido por Cerotoma arcuata (Coleoptera; Chrysomelidae). Um isolado deste vírus, denominado CpSMV-SP, proveniente de plantas de Vigna luteola coletadas no litoral sul do Estado de São Paulo, está sendo estudado no Laboratório de Fitovirologia e Fisiopatologia/ Instituto Biológico. O objetivo do presente trabalho consistiu em uma avaliação da preferência alimentar de $C$. arcuata em cultivares de soja e da suscetibilidade destes cultivares ao vírus. $\mathrm{Na}$ avaliação da preferência alimentar, os ensaios foram feitos com discos foliares colocados em placas de Petri, cobertas por copos plásticos, constituindo "arenas". Introđuziu-se um coleóptero em cada "arena", realizando-se testes em confinamento, tanto com múltipla escolha (11 cultivares) como sem (um único cultivar). Os cultivares avaliados foram: 'BR-4', 'COODEPEC-201', 'EMBRAPA-48', 'EMBRAPA-59', 'IAC-17','IAC-15-1', 'IAC-20', 'IAC-100', 'IAS-5', 'IGUAÇU' e 'PL-1'. Os ensaios de transmissão foram feitos através de inoculação mecânica e pelo vetor $C$. arcuata. Os resultados mostraram que os 11 cultivares são suscetíveis ao vírus, quando a inoculação é feita por extrato (mecanicamente). Ocorre também transmissão pelo colé́ptero, porém não no caso de IAC-20 e IAC-100. C. arcuata alimenta-se de todos os cultivares, em maior ou em menor intensidade, exceção feita ao IAC-20, fato que pode justificar a não transmissẫo pelo menos para estas plantas. Considerando que a disseminaçăo natural do CpSMV-SP ocorre através do vetor, e que ela é negativa para os dois cultivares referidos, pode-se recomendar preferencialmente o seu plantio, no Estado de São Paulo.
\end{abstract}

Palavras-chave - soja, mosaico severo do caupi, colé́ptero, preferência alimentar

ABSTRACT - (Comparison among soybean cultivars concerning the feed preference of Cerotoma arcuata and susceptibility to an isolate of (pSMV). In Brazil, among the viruses causing crop losses in

I Instituto Biológico, Centro de Sanidade Vegetal, Laboratório de Fitovirologia e Fisiopatologia, Av. Conselheiro Rodrigues Alves 1252, CEP 04014-002, São Paulo, SP, Brasil

2 Estagiário

3olsista PIBIC/CNPq 
leguminous plants, mainly on soybean (Glycine max), bean (Phaseolus vulgaris) and cowpea (Vigna unguiculata), the cowpea severe mosaic virus (CpSMV), vectored by Cerotoma arcuata, is one of the best known. An isolate of CpSMV, named CpSMV-SP, was found on the Southern coastal region of São Paulo State infecting Vigna luteola, and has been subsequently studied at the Laboratory of Phytopathological Virology and Physiopathology of the Biological Institute. The feeding preference trials of $C$. arcuata, on soybean cultivars, were performed as follows: leaf discs were placed in Petri dishes covered with plastic glass-shaped lids to form an "arena" in which a single beetle was confined, taking into consideration multiple choice (11 cultivars), or not (a sole cultivar). The tested cultivars were 'BR-4', 'COODEPEC-201', 'EMBRAPA-48', 'EMBRAPA-59', 'IAC-17', 'IAC-15-1', 'IAC-20', 'IAC-100', 'IAS-5', 'IGUACUU' and 'PL-1'. For the susceptibility evaluation of cultivars, CpSMV-SP was $C$. arcuata and mecanically inoculated. Results showed that the feeding preference of $C$. arcuata varied and that the vector did not feed on IAC- 20 only. When mecanicaly inoculated, all cultivars were susceptible to CpSMV-SP however, IAC-20 and IAC-100 were not infected when inoculated by $C$. arcuata. The former, probably due to the vector not fed on it, and the latter because the vector presented low or no efficiency. Considering these results and the natural occurrence of CpSMV-SP, the use of the cultivars IAC-20 and IAC-100 could be recommended for São Paulo State.

Key words - soybean, cowpea severe mosaic virus, beetle, feeding preference

\section{Introdução}

A cultura de soja [Glycine max (L.) Merril.] representa grande percentual da produção agrícola nacional, sendo uma das principais fontes de proteína para a população brasileira, especialmente nas regiões centro-sul, sul e sudeste. A área plantada é de 11.299.199ha, com produção anual de 25.687.137t (IBGE 1997).

Apesar da grande produção, a soja é uma das culturas mais atingidas por pragas e doenças. No caso das pragas, merecem destaque lepidópteros (Anticarsia gemmatalis, Spodoptera spp.), hemípteros (Nezara viridula, Piezodorus guidinii e Euchistus heros) e coleópteros (Diabrotica speciosa, Cerotoma sp. e Colaspis sp.) (Gazzoni \& Yorinori 1995). As doenças estão entre os principais fatores que afetam o rendimento da cultura. No período de 1970 a 1998 , foram registradas mais de 40 doenças provocadas principalmente por fungos, bactérias e vírus. Apenas no ano de 1998, a estimativa de perdas associadas a doenças foi de $6.440 .600 \mathrm{t}$, em uma produção total de $31.355 .800 \mathrm{t}$ (Yorinori 1998), números que mostram o elevado prejuízo econômico causado por patógenos nesta cultura (cerca de 20\%).

Em março de 1990, plantas de Vigna luteola Jacq. (Leguminosae, Fabaceae) com intenso mosaico amarelo e deformações foliares foram coletadas no município de Praia Grande, SP. Sintomas semelhantes haviam sido observados, na mesma espécie, em Peruíbe, SP (Barradas \& Chagas 1982), tendo-se mostrado que se tratava de uma virose induzida por um geminivírus, transmitido experimentalmente apenas pela "moscabranca" (Bemisia tabaci) e por enxertia. Com base na semelhança de sintomatologia, pensou-se a princípio que o mesmo vírus tivesse sido constatado, em 1990, em outra localidade do litoral paulista. Entretanto, resultados prévios sugeriram tratar-se de um Comovirus, pois sua transmissão ocorreu tanto mecanicamente como por enxertia e pelo coleóptero crisomelídeo Cerotoma arcuata, e observações ultraestruturais de cortes foliares do material original mostraram inúmeras partículas virais isométricas, de aproximadamente 28nm, nos vacúolos (Barradas et al. 1991). 
Posteriormente, caracterizou-se este vírus como um novo isolado do mosaico severo do caupi ("cowpea severe mosaic Comovirus"- CpSMV) e, por ter sido encontrado no Estado de São Paulo, passou-se a denominá-lo CpSMV-SP (Salas et al. 1996a; 1996b). Salas (1998) mostrou que o círculo de hospedeiras do CpSMV-SP é restrito, pois de inúmeras espécies inoculadas mecanicamente (famílias Amaranthaceae, Chenopodiaceae, Cucurbitaceae, Leguminosae e Solanaceae) apenas representantes de Leguminosae e Chenopodiaceae são suscetíveis. No caso de leguminosas, responderam com sintomas sistêmicos: Canavalia ensiformis, Glycine javanica, G. max, Macroptilium lathyroides, Phaseolus lunatus, P. vulgaris, Vigna luteola, V. mungo, V. unguiculata. Quanto à Chenopodiaceae, Chenopodium amaranticolor apresentou somente sintomas locais.

O objetivo do presente trabalho é verificar a resposta de alguns cultivares de soja, tanto à inoculação pelo CpSMV-SP como ao dano causado pelo coleóptero Cerotoma arcuata, que é uma das pragas da cultura, além de ser vetor do vírus.

\section{Material e métodos}

Ensaios de preferência alimentar - Para avaliar a preferência do inseto utilizaramse discos da $1^{a}$ folha trifoliolada de plantas de soja (Glycine max), no $3^{\circ}$ estádio fenológico da fase vegetativa (estádio $\mathrm{V}_{2}$, cf. Yorinori 1998). Os cultivares empregados, incluídos entre aqueles comumente plantados no Estado de São Paulo, foram: 'BR-4', 'COODEPEC-201', 'EMBRAPA-48', 'EMBRAPA-59', 'IAC-17', 'IAC-15-1', 'IAC-20', 'IAC-100', 'IAS-5', 'IGUAÇU' e 'PL-1'.

A técnica usada baseou-se no trabalho de Risch (1976): o experimento foi realizado em placas de Petri $(9,5 \mathrm{~cm}$ diâm $\times 0,5 \mathrm{~cm}$ alt.) forradas com papel de filtro umedecido, constituindo uma câmara úmida, com auxílio de copos plásticos transparentes (capacidade $300 \mathrm{ml}$ ), furados com alfinete para permitir a ventilação, emborcados sobre as placas. Colocou-se algodão umedecido para evitar a dessecação, tanto dos discos foliares (diâm. $=1,7 \mathrm{~cm}$ ) como dos insetos. Cada placa de Petri constituiu uma "arena" (Fig. 1).

Os coleópteros (Cerotoma arcuata, vaquinha-preta-e-amarela-da-soja) foram coletados em culturas de feijão, nos municípios de Campinas, Piracicaba e Salto de Pirapora, SP. Os exemplares foram levados ao laboratório e as colônias foram mantidas com alimentação natural (folhas de feijão - Phaseolus vulgaris - 'Carioca') em câmaras climatizadas, nas seguintes condições: temperatura $25 \pm 2^{\circ} \mathrm{C}$; umidade relativa $80 \pm$ $10 \%$ e fotofase de $12 \mathrm{~h}$.

Foram realizados dois tipos de ensaios, em confinamento: com e sem múltipla escolha. No primeiro caso, 11 discos foliares (um de cada cultivar), sustentados por alfinetes, foram colocados na placa de Petri, eqüidistantes do centro. No segundo, empregaram-se seis discos foliares do mesmo cultivar. Os discos permaneceram em água destilada por duas horas, antes do início do teste, a fim de não perderem a turgidez. Nos dois ensaios, apenas um exemplar de Cerotoma arcuata (macho ou fêmea) era introduzido na "arena".

Cada experimento constou de 10 "arenas" (múltipla escolha) ou 22 (sem múltipla escolha) e foi repetido duas vezes. 

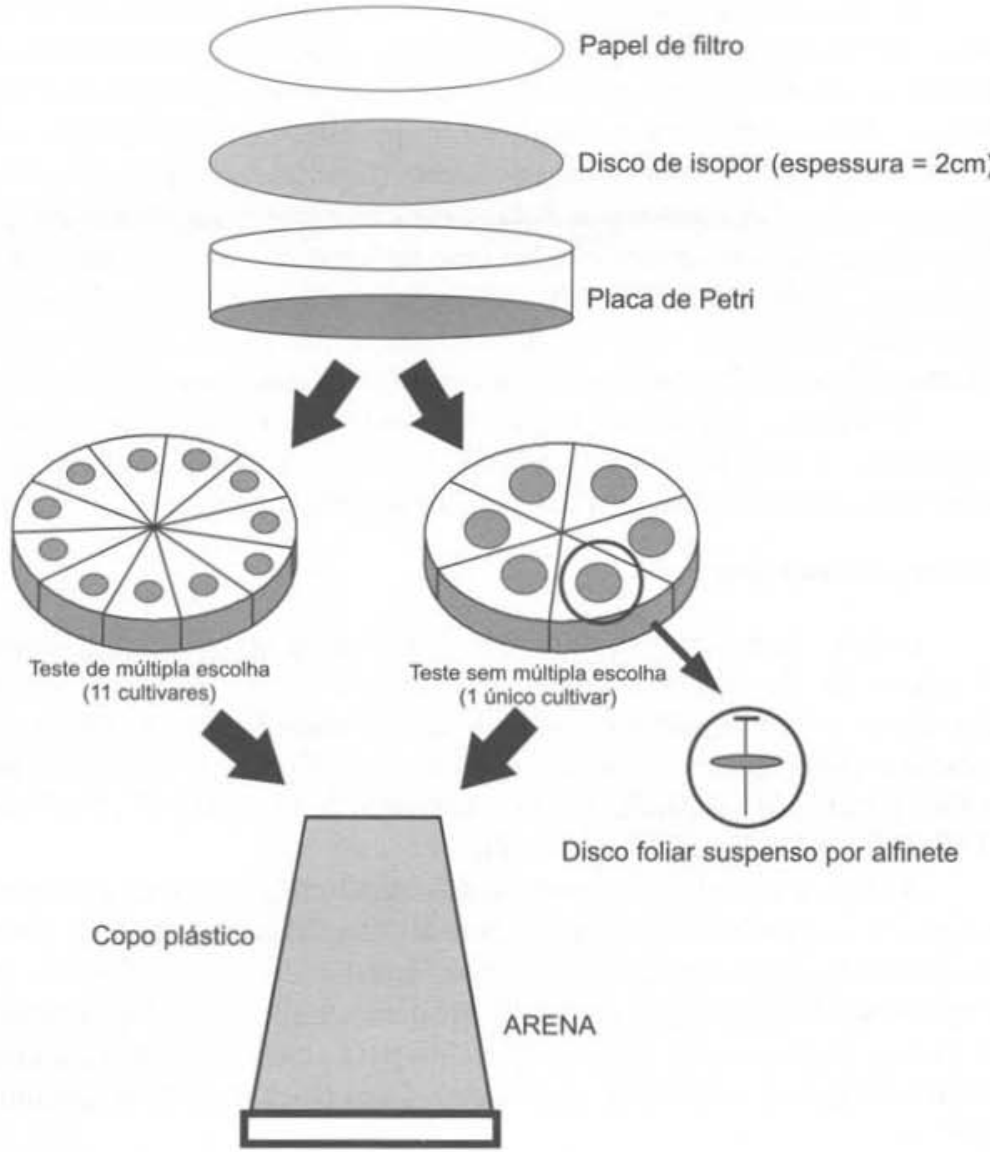

Disco foliar suspenso por alfinete

Figura 1. Representação esquemática da montagem das "arenas"

A avaliação de preferência foi realizada através da diferença entre a área inicial do disco foliar e a área final, após o dano causado pelo inseto (Lara 1991). Para determinação da área, os discos eram desenhados sobre papel milimetrado, antes de serem colocados nas "arenas", $22 \mathrm{~h}$ após o início do experimento.

Testes de transmissão - inoculação mecânica - Foram inoculados os mesmos cultivares de soja referidos no item 1 .

A fonte de vírus constou de tecido foliar desidratado de Macroptilium lathyroides, feijão-de-rola (Leguminosae, Fabaceae), mantido através de armazenamento a aproximadamente $-20^{\circ} \mathrm{C}$ (Barradas 1992).

$\mathrm{O}$ inóculo constou de extrato preparado a partir deste material (armazenado por dois anos), macerado em tampão fosfato $0,5 \mathrm{M}, \mathrm{pH} 7,5$, com carvão ativado. As plantas (10 de cada cultivar) foram previamente polvilhadas com o abrasivo "carburundum" $\mathrm{e}$ 
inoculadas 15 dias após o transplante das sementes pré-germinadas, no $4^{\circ}$ estádio da fase vegetativa, quando apresentavam o terceiro nó e a segunda folha trifoliolada (estádio $\mathrm{V}_{3}$, cf. Yorinori 1998). A inoculação foi feita sempre na segunda folha trifoliolada.

A evolução de sintomas foi acompanhada durante 14 dias, realizando-se observações diárias, principalmente na folhagem das plantas. O controle constou de plantas "inoculadas" apenas com tampão fosfato.

A fim de comprovar a presença do vírus, foram realizados testes de recuperação (retroinoculações) em plantas de Phaseolus lunatus, feijão-de-lima (Leguminosae, Fabaceae), hospedeira que inicialmente responde com lesões locais ao CpSMV-SP (Salas et al. 1996a; Salas 1998). Também foram feitos testes sorológicos de dupla difusão, empregando-se gel de ágar preparado com $0,85 \%$ de agarose, $0,85 \%$ de $\mathrm{NaCl}$ e $0,05 \%$ de $\mathrm{NaN}_{3}$ (p/v), de acordo com Lima \& Nelson (1974) e Brioso et al. (1994). O preparo do antissoro contra o CpSMV-SP encontra-se descrito em Salas et al.(1996b).

Testes de transmissão - inoculação pelo vetor Cerotoma arcuata - Adultos de $C$. arcuata, coletados em campo, foram trazidos ao laboratório, onde se procedeu à manutenção das colônias em plantas de feijão, conforme descrito no item 1 .

Após a adaptação das colônias no laboratório por aproximadamente 10 dias, alguns exemplares do coleóptero foram colocados em plantas comprovadamente sadias de $P$. vulgaris, para verificar se estavam isentos de vírus (teste de desinfecção).

Foram separados coleópteros adultos machos e fêmeas para a realização dos testes de transmissão, empregando-se um inseto/planta hospedeira. A separação por sexo baseou-se na dilatação do segundo antenômero, presente apenas nos machos (Gonzalez et al. 1982) e também na coloração da área situada entre os olhos (preta nos machos e amarela nas fêmeas) (Holcomb \& Fulton 1978).

Os coleópteros foram alimentados por 12 horas (período de acesso à aquisição) em plantas-fonte de Glicine max 'IAC-100' com sintomas sistêmicos após a inoculação mecânica pelo CpSMV-SP. A seguir, foram transferidos para plantas-teste comprovadamente sadias com idade de 15 dias após a semeadura, até comprovar a sua alimentação (período de acesso à inoculação), nos 11 cultivares. Empregaram-se 20 plantas de cada cultivar.

O controle negativo constou de plantas onde se colocaram besouros não virulíferos, isto é, não submetidos ao período de aquisição. Também foram inoculadas plantas mecanicamente (por extrato), para se comprovar se as fontes realmente continham o vírus, constituindo o controle positivo.

Os insetos foram eliminados manualmente após o experimento.

Realizaram-se avaliações diárias, observando-se o aparecimento ou não de sintomas durante 14 dias, procedendo-se a uma retroinoculação, ao final deste período, em plantas de feijão 'Carioca', para confirmar a presença do vírus.

\section{Resultados e discussão}

As percentagens de área foliar consumida pelo coleóptero, tanto em confinamento sem múltipla escolha (Fig. 2A), como com múltipla escolha (Fig. 2B), variaram de acordo com o sexo do inseto e o cultivar de soja. 
A

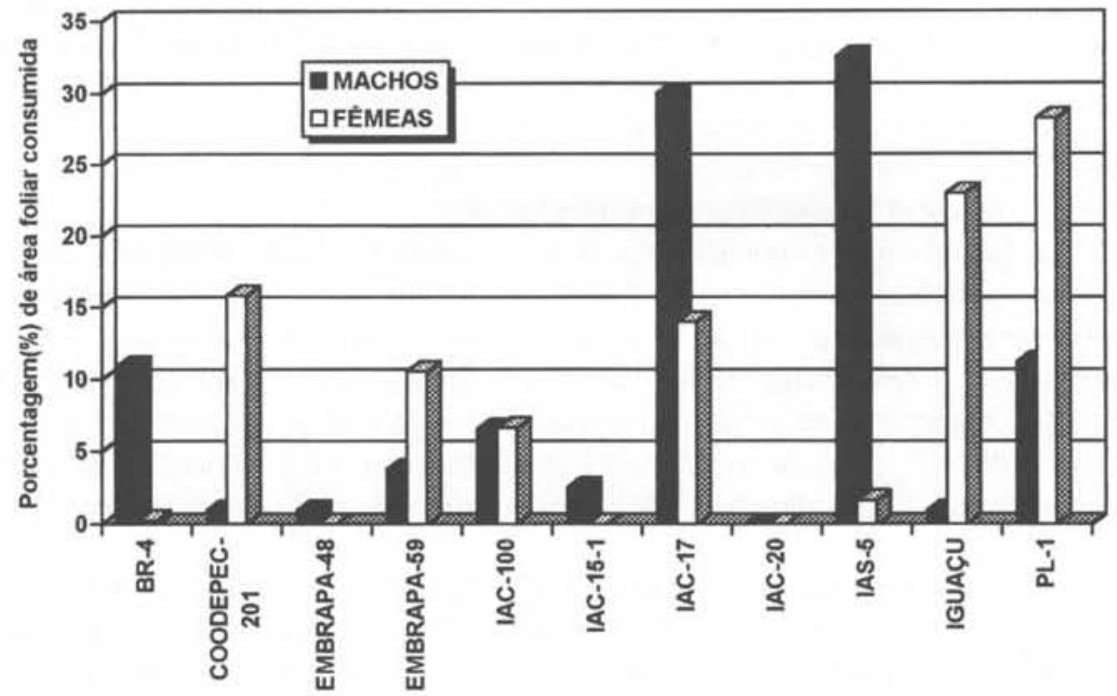

Cultivares

B

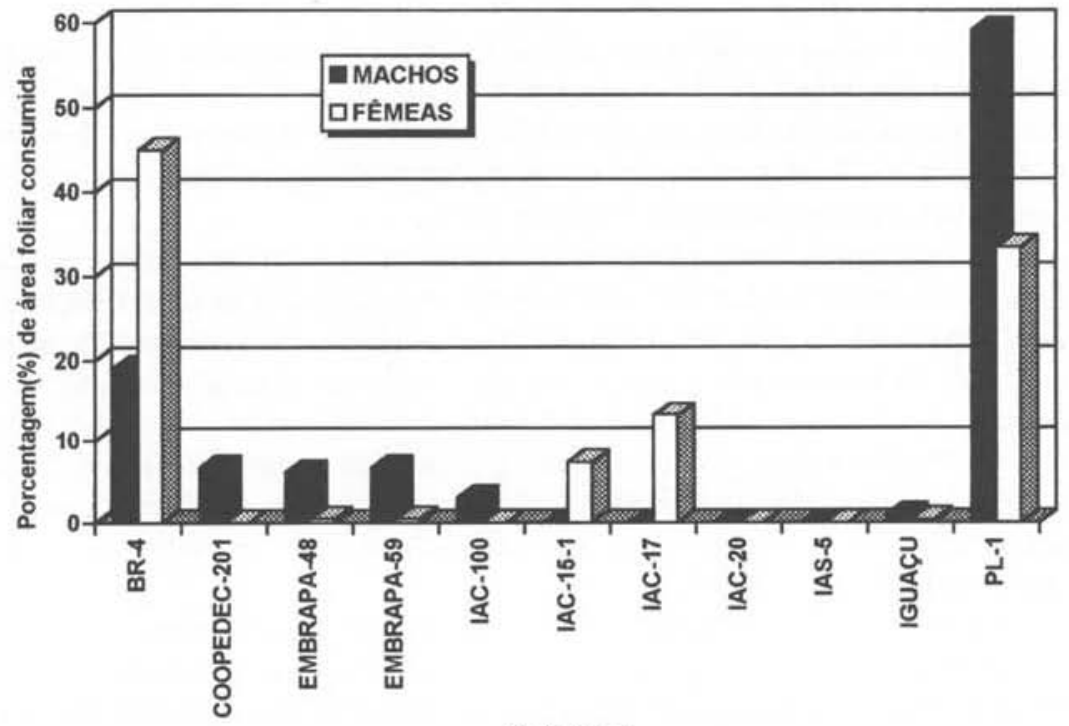

Cultivares

Figura 2. Comparação entre machos e fêmeas de Cerotoma arcuata quanto à alimentação em diferentes cultivares de soja. Percentagem de área foliar consumida de cada cultivar. A. Ensaio sem múltipla escolha (somatório da área de 24 discos foliares). B. Ensaio com múltipla escolha (somatório da área de 20 discos foliares). 
Nos testes sem múltipla escolha os dois cultivares mais atacados pelos machos foram IAC-17 e IAS-5, e os preferidos pelas fêmeas foram PL-1 e Iguaçu. No caso de múltipla escolha os mais consumidos foram PL-1 e BR-4, por machos e fêmeas, respectivamente.

Em trabalho semelhante, Rossetto et al. (1981), avaliando os danos induzidos por coleópteros em diferentes cultivares e introduções de soja, verificaram que $C$. arcuata alimentou- se indiferentemente dos cultivares e introduções, sem preferência, enquanto outro crisomelídeo (Diabrotica speciosa) preferiu os cultivares comerciais (Paraná e Santa Rosa).

Os resultados do presente trabalho confirmam dados da literatura quanto ao fato de que a preferência alimentar é altamente específica, sendo diferente para cada espécie de coleóptero (Risch 1976; Heyer et al. 1990; Panizzi \& Parra 1991) e para cada sexo de uma mesma espécie (Smith et al. 1979).

Dentre os 11 cultivares, os insetos alimentaram-se de todos, com exceção do IAC-20 (Fig. 2). O cultivar IAS-5 não foi consumido, nem por machos nem por fêmeas, nos testes com múltipla escolha (Fig. 2B); entretanto, foi um dos preferidos pelos machos, nos ensaios sem múltipla escolha (Fig. 2A).

Não se constatou diferença no consumo foliar por machos e fêmeas, considerando o somatório de todos os cultivares (Fig. 3A e 3B), embora alguns autores afirmem que fêmeas adultas de coleópteros se alimentam mais que os machos, devido à maior necessidade de alimento para a realização de posturas (Panizzi \& Parra 1991; Salas 1998).

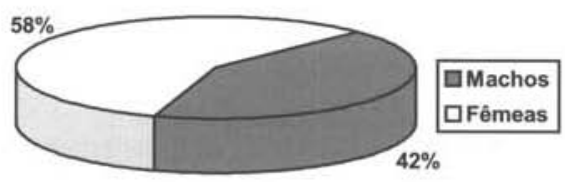

A

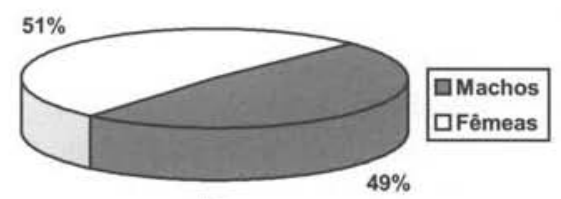

B

Figura 3. Comparação entre machos e fêmeas de Cerotoma arcuata quanto à alimentação em soja. Somatório geral da área foliar consumida (11 cultivares). A. Ensaio sem múltipla escolha; B. Ensaio com múltipla escolha.

O CpSMV-SP induziu sintomas sistêmicos nos 11 cultivares de soja, mostrando que todos são suscetíveis, por inoculação mecânica (Tab.1). Entretanto, não houve aparecimento de sintomas nos cultivares IAC-100 e IAC-20 (e nem o vírus pôde ser recuperado das plantas), quando a transmissão foi realizada por $C$. arcuata. Tal fato pode ser explicado pela não preferência por estes cultivares: $0 \%$ de consumo foliar em relação a IAC-20 e menos de 10\% em relação a IAC-100 (Fig. 2).

De forma geral, os sintomas são semelhantes aos descritos na literatura para várias espécies de leguminosas infectadas pelo CpSMV, variando de mosaico leve a severo, 
clareamento de nervuras, nanismo e deformação foliar (De Jager 1979). Apenas o cultivar IAC-17 reagiu com necrose de topo (queima-do-broto), que foi o efeito mais drástico do vírus, levando as plantas à morte.

Os sintomas apresentados pelas plantas, após inoculação mecânica e através do vetor, foram semelhantes, com a ressalva de que, ao final de 14 dias, ocorreu nanismo na maioria dos cultivares inoculados pelo vetor, e este sintoma não foi observado no caso da inoculação mecânica (Tab.1).

O surgimento dos sintomas deu-se aos seis dias após a inoculação. Em dois cultivares (PL-1 e EMBRAPA-59), as plantas inoculadas por extrato manifestaram sintomas neste período, enquanto houve demora de 14 dias naquelas inoculadas pelos besouros. Por outro lado, em outros três cultivares (BR-4; EMBRAPA-48 e IAC-15-1) verificou-se situação inversa: aparecimento de sintomas aos seis dias nas plantas inoculadas pelo vetor, e aos 10 ou 14 dias naquelas inoculadas mecanicamente (Tab. 1).

$\mathrm{Na}$ epidemiologia dos vírus de plantas, as hospedeiras naturais desempenham papel muito importante, pois atuam como fonte de inóculo (Matthews 1991). No caso específico do CpSMV, plantas da vegetação espontânea - invasoras de culturas - têm sido relatadas como reservatórios, por exemplo: em Porto Rico, Phaseolus lathyroides (=Macroptilium lathyroides); na Costa Rica, Vigna vexillata; na região centro-sul dos Estados Unidos, Desmodium canescens (Alconero \& Santiago 1973; Gergerich \& Scott 1996).

No Brasil, também é comum a ocorrência do CpSMV em espécies invasoras. Assim, já foram descritas como hospedeiras: Calopogonium mucunoides e Centrosema pubescens (Lin et al. 1982); Dolichus biflorus, Sesbania sp. e Trigonella foenumgraecum (Caner et al. 1969); Macroptilium lathyroides (Lima \& Nelson 1974); Pueraria sp. (Rios 1984) e Psophocarpus tetragonolobus (Kitajima et al. 1979). Relação das hospedeiras naturais do vírus, com descrição resumida dos sintomas gerais, foi apresentada por Brioso et al. (1994).

O CpSMV-SP difere da estirpe-padrão principalmente no círculo de hospedeiras pois, enquanto este isolado de Vigna luteola infecta, experimentalmente, grande número de cultivares de soja e feijão, e número reduzido de cultivares de caupi (Salas et al. 1996a; Salas 1998), a estirpe-padrão afeta inúmeros cultivares de caupi (De Jager 1979).

Considerando a elevada suscetibilidade ao CpSMV-SP dos cultivares de soja plantados no Estado de São Paulo, a ampla ocorrência e eficiência do vetor e a ocorrência de vários reservatórios naturais, a disseminação do vírus, em áreas de cultivo de soja, é um risco potencial.

Assim, pode-se concluir que, de forma geral, os 11 cultivares de soja relacionados no trabalho são suscetíveis ao CpSMV-SP, respondendo com sintomas sistêmicos. O vírus é transmitido tanto por inoculação mecânica como por machos e fêmeas adultos do crisomelídeo Cerotoma arcuata. Entretanto, notam-se diferenças na resposta, de acordo com o tipo de inoculação: os cultivares IAC-20 e IAC-100 mostram resultados negativos em testes de transmissão pelo coleóptero. Tendo em vista que, na natureza, o vírus se dissemina através do vetor, pode-se recomendar preferencialmente o plantio destes dois cultivares não suscetíveis à transmissão. 


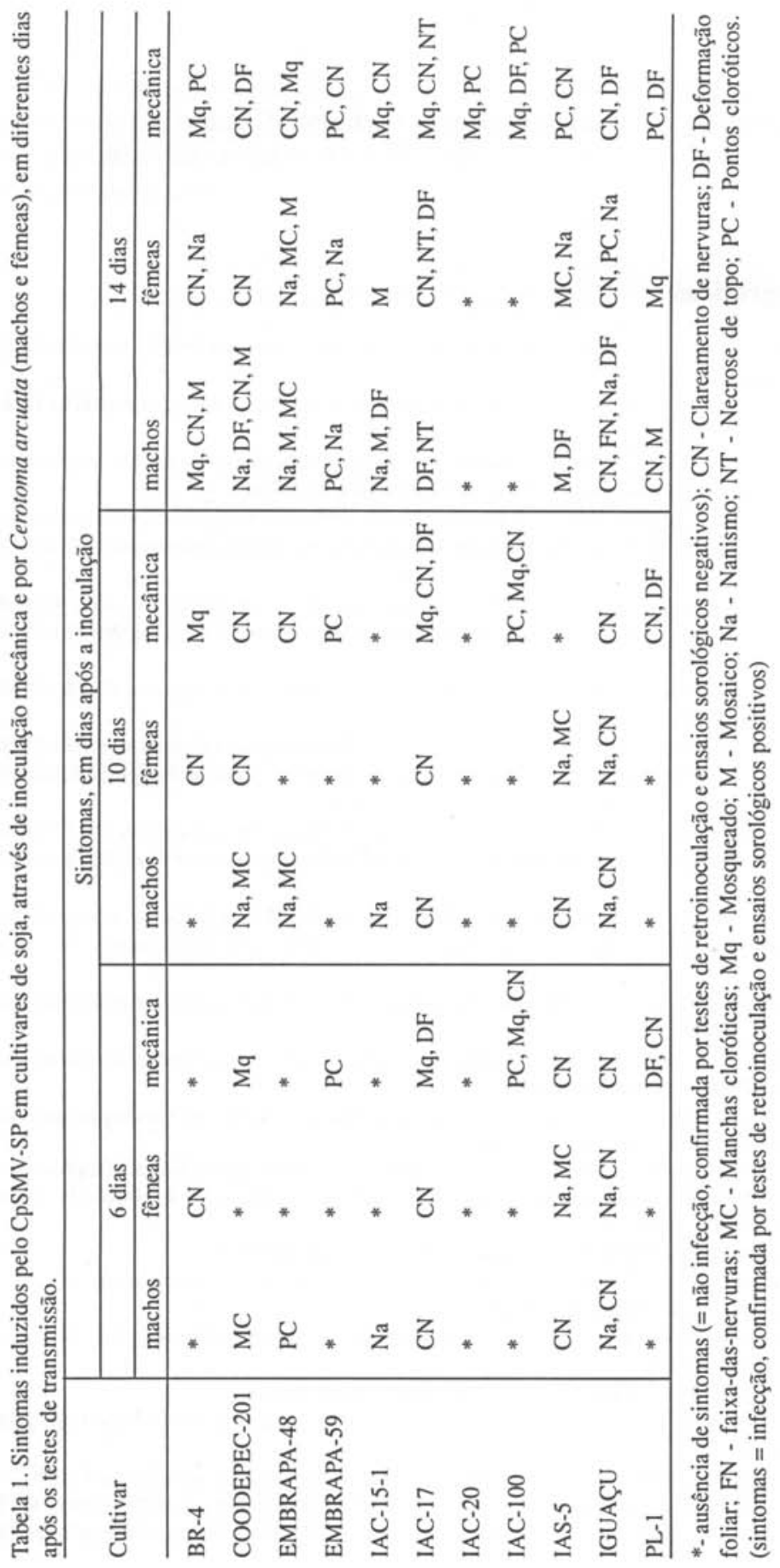




\section{Agradecimentos}

Os autores agradecem ao Dr. Nelson Braga, da Seção de Leguminosas do Instituto Agronômico de Campinas, SP, e ao Pesquisador Científico Cláudio Marcelo G. de Oliveira, da Seção de Nematologia do IB, SP, pelo fornecimento das sementes dos diversos cultivares de soja; ao Dr. César Martins Chagas, do Laboratório de Microscopia Eletrônica do IB, SP, pela elaboração do texto em Inglês.

\section{Referências bibliográficas}

Alconero, R. \& Santiago, A. 1973. Phaseolus lathyroides as a reservoir of cowpea mosaic virus in Puerto Rico. Phytopathology 63: 120-123.

Barradas, M. M. 1992. IB mantém coleção de fitovírus. Comunicação da Pesquisa Agropecuária 10(1): 9.

Barradas, M. M. \& Chagas, C. M. 1982. Mosaico dourado de Vigna luteola (Jacq.) Bentham., leguminosa da vegetação espontânea. Arquivos do Instituto Biológico 49(1/4): 85-88.

Barradas, M. M.; Salas, F. J. S.; Buitrón, I. P. G. \& Oliveira, J .M. 1991. Morfologia e transmissão de um vírus isolado de Vigna luteola. Pp.13. In: Anais do IV Seminário sobre pragas e doenças do feijoeiro, Campinas.

Brioso, P. S. T.; Duque, F. F.; Sayão, F. A. D.; Louro, R. P.; Kitajima, E. W. \& Oliveira, D. E. 1994. Vírus do mosaico severo do caupi - infecção natural em mungo verde, Vigna radiata. Fitopatologia Brasileira 19(3): 420-429,

Caner, J.; Silberschmidt, K. \& Flores, E. 1969. Ocorrência do vírus do mosaico da Vigna no Estado de São Paulo. Biológico 35(1): 13-16.

De Jager, C. P. 1979. Cowpea severe mosaic virus. C.M.I./ A.A.B. Descriptions of plant viruses $\mathrm{n}^{\circ} 209$.

Gazzoni, D. L. \& Yorinori, J. T. 1995. Manual de identificação de pragas e doenças da soja. EMBRAPA - SPI (Manuais de Identificação de Pragas e Doenças, 1), Brasília.

Gergerich, R. C. \& Scott, H. A. 1996. Comoviruses: transmission, epidemiology and control. Pp.77-98. In: B. D. Harrison \& A . F. Muranti (Eds.), The plant viruses. Polyhedral virions and bipartite genomes. Plenum Press, New York.

Gonzalez, R.; Cardona, C. \& Van Schoonhoven, A. 1982. Morfologia y biologia de los crisomelídeos Diabrotica balteata Le Conte y Cerotoma facialis Erickson como plagas del frijol comum. Turrialba 32(3): $257-264$.

Heyer, W.; Caballero Grande, R. \& Cruz, B. 1990. Área foliar consumida por crisomélidos en frijol. Ciencias de la Agricultura 39: 39-42.

Holcomb, C. E. \& Fulton, J. P. 1978. Rearing the bean leaf beetle, Cerotoma trifurcata, for plant virus vector studies. Plant Disease Reporter 62(1): 12-14.

IBGE - Instituto Brasileiro de Geografia e Estatística. Levantamento sistemático da produção agrícola. julho/97. www.ibge.gov.br (data de consulta: 20/09/97).

Kitajima, E. W.; Noda, H.; Lin, M. T. \& Costa, C. L. 1979. Um mosaico em feijão-de-asa (Psophocarpus tetragonolobus) causado por um isolado do subgrupo severo do vírus do mosaico da Vigna. Fitopatologia Brasileira 4: 519-524.

Lara, F. M. 1991. Princípios de resistência de plantas a insetos. Ícone, São Paulo.

Lima, J. A. A. \& Nelson, M. R. 1974. Purificação e identificação sorológica do "cowpea mosaic virus" em Vigna sinensis Endl. no Ceará . Ciência Agronômica 3: 5-8.

Lin, M. T.; Anjos, J. R. N. \& Rios, G. P. 1982. Cowpea severe mosaic virus in five legumes in Central Brazil. Plant Disease 66: 67-70.

Matthews, R. E. F. (Ed.) 1991. Plant Virology. $3^{\text {nt }}$ ed. Academic Press, London.

Panizzi, A. R. \& Parra, J. R. P. 1991. Ecologia nutricional de insetos e suas implicações no manejo de pragas. Manole, São Paulo.

Rios, G. P. 1984. Resistência ao vírus do mosaico severo do caupi. Fitopatologia Brasileira 9: 309

Risch, S. 1976. Effect of variety of cowpea (Vigna unguiculata L.) on feeding preferences of three chrysomelid beetles, Cerotoma ruficornis rogersi, Diabrotica balteata and Diabrotica adelpha. Turrialba 26 (4): 327-330. 
Rossetto, C. J.; Nagai, V.; Igue, T.; Rossetto, D. \& De Miranda, M. A. C. 1981. Preferência de alimentaçāo de adultos de Diabrotica speciosa (Germar) e Cerotoma arcuata (Oliv.) em variedades de soja. Bragantia 40: $179-183$.

Salas, F. J. S. 1998. Criação de Cerotoma arcuata Oliv. (Coleoptera; Chrysomelidae) e transmissão de um isolado do vírus do mosaico severo do caupi. Dissertação de Mestrado. ESALQ, USP, Piracicaba.

Salas, F. J. S.; Barradas, M. M.; Sousa, A. E. B. A. \& Lima, J. A. A. 1996a Vigna luteola, a natural host of cowpea severe mosaic virus (CpSMV) in São Paulo State, Brazil. Pp. 280, In: Resumos do $8^{\circ}$ Encontro Nacional de Virologia, São Lourenço.

Salas, F. J. S.; Lima, J. A. A.; Sousa, A. E. B. A. \& Barradas, M. M. 1996b. Purification and serology of a strain of cowpea severe mosaic virus isolated from Vigna luteola in São Paulo State, Brazil.Pp. 279. In: Resumos do $8^{\circ}$ Encontro Nacional de Virologia, São Lourenço.

Smith, C. M.; Wilson, R. F. \& Brim, C. A. 1979. Feeding behavior of mexican bean beetle on leaf extracts of resistant and susceptible soybeans genotipes. Journal of Economic Entomology 72(3): 374 - 377 .

Yorinori, J. T. 1998. Estratégias de controle das doenças da soja. Correio Agrícola 2: 8-14. 